\title{
NILAI-NILAI BUDAYA DALAM TEKS RAJA $\boldsymbol{A} L \boldsymbol{A M}$
}

\author{
Chairil Effendy \\ Program Studi Pendidikan Bahasa Indonesia FKIP Untan \\ Email: chairil.eff@gmail.com
}

\begin{abstract}
Abstraksi
Teks Raja Alam (RA) adalah salah satu teks sastra lisan Melayu Sambas. Teks ini pernah hidup dalam tradisi bedande', satu tradisi bersastra yang sudah hilang. Teksnya disampaikan dengan cara didendangkan. Bahasa yang digunakan adalah Bahasa Melayu Sambas yang diperkaya dengan Bahasa Arab, idiolek, dan bentuk-bentuk stilisasi sehingga bahasanya sangat khas, ialah bahasa bedande'. Teks ini juga kaya dengan formula dan kontruksi formulaik. Teks $R A$ memiliki struktur yang utuh, yang terdiri atas bagian awal, bagian tengah, dan bagian akhir. Totalitas struktur teksnya diapit oleh eksordium dan doa selamat. Eksordium berfungsi mengantarkan pendendangan teks, sedangkan doa selamat berfungsi mengakhiri pendendangan teks. Teks $R A$ tidak muncul dari kekosongan budaya. Sebagai teks yang lahir dari tengah masyarakat Melayu Sambas, tentulah teks ini mengandung nilai-nilai budaya Melayu Sambas. Berdasarkan kajian yang dilakukan terdapat nilai budaya yang berkaitan dengan hakikat kehidupan, hakikat hubungan manusia dengan alam sekitar, hakikat hubungan sesama manusia, hakikat hubungan manusia dengan ruang dan waktu, dan hakikat hubungan manusia dengan kerja.
\end{abstract}

Kata Kunci: Nilai, Budaya, Teks Raja Alam

\section{PENDAHULUAN}

Bangsa Indonesia beruntung karena memiliki khaza $\neg$ nah sastra lama dalam jumlah besar. Sastra lama itu ada yang tersimpan dalam bentuk tulis atau naskah, ada yang tersimpan dalam bentuk lisan. Sebagian teks tulis kini tersimpan di sejumlah perpustakaan dan museum di dalam maupun di luar negeri, sebagian lainnya menjadi koleksi perorangan (Baried dkk., 1985a:5). Dalam pada itu, sebagian teks lisan ada yang telah diawetkan dalam bentuk tulis, sebagian lagi masih tersimpan di dalam benak tukang cerita atau penyimpan tradisi lisan lainnya.

Salah satu masyarakat Nusantara yang sampai kini masih memelihara sastra lisan adalah masyarakat Melayu Sambas (selanjutnya: Sambas). Masyarakat yang mendiami pesisir utara Kalimantan Barat itu masih aktif menuturkan atau mendendangkan sastra lisan, baik prosa mau $\neg$ pun puisi, dalam berbagai tradisi. Penuturan sastra lisan dan pelisanan sastra tulis itu dilakukan oleh pria maupun wanita. Fungsi penuturannya bermacam-macam, tetapi yang lebih dominan adalah fungsi hiburan (Effendy, 1992:258-64).

Salah satu bentuk sastra lisan di tengah masyara $\neg$ kat ini adalah prosa. Dilihat dari cara pementasannya, jenis sastra tersebut terbagi menjadi dua kelompok, ia $\neg$ lah becerite dan bedande'. Keduanya relatif identik dengan pembagian "sastra lisan murni" dan "sastra lisan setengah murni" (Hutomo, 1993:60). Teks-teks becerite dituturkan secara normal dengan dukungan ekspresi wajah dan gerakgerik tubuh (Kendon, 1992:179), sedangkan teks-teks bedande' dipentaskan dengan cara didendangkan.

Salah satu teks bedande' yang digemari masyarakat Sambas, khususnya di kecamatan Sejangkung dan Teluk Keramat, adalah Raje Ngalam atau 'Raja Alam' (selanjut $` n y a:$ RA) . Teks ini terdiri atas tujuh episode, ialah Raje Sentang Mude (RSM), Raje Ngalam (RN), Ngawang Mega Sakti (NMS), Ngawang Kamaruden (NKam), Raje Saeh (RS), Ngawang Kebaren (NKeb), dan Ngawang Kesokme (NKes). Se $\neg$ bagai satu fakta mental (mentifact menurut Kartodirdjo, 1992:16), cerita mengenai 
ketujuh tokoh di atas dipercayai oleh masyarakat pemiliknya benar-benar pernah terjadi di masa lalu (Liaw, 1975:14). Cerita tentang Raja Alam ini terdapat juga di dalam teks Si Gentar Alam, Dayang Dandi, Wan Unggal, dan Anak Mayang Susun Delapan Susun Sembilan Anak Cucu Si Gentar Alam.

Teks $R A$ diperkirakan mengandung nilai-nilai budaya. Fungsi pada nilai-nilai itu diperkirakan sebagai faktor yang menyebabkan teksnya dianggap sakral dan tetap dipentaskan hingga kini. Maka, ia perlu diketahui dalam rangka peningkatan pemahaman masyarakat awam maupun masyarakat ilmiah mengenai keanekaragaman budaya Nusantara, yang pada hakikatnya menjadi landasan bagi kebudayaan Indonesia. Bagi pembaca masa kini, ketersediaan $R A$ dapat dijadikan "layar proyeksi" (Hassan, 1985:11) yang memperlihatkan "pandangan dunia" (Goldmann, 1981:23-4; Osman, 1988:138) masyarakat di masa lalu sebagai bahan perbandingan bagi kehidupan di masa kini (Hassan, 1985:11; Laurenson dalam Swingwood, 1972: 13-7).

Teks $R A$ muncul dari masa lampau. Dalam sejarah transmisinya, teks itu telah mendapat berbagai tanggapan dari para penikmatnya. Hadirnya teks-teks variabel, yang diperkirakan melibatkan $R A$ dalam proses penciptaannya, menunjukkan bahwa teks itu memiliki peranan dalam dinamik sistem dan sejarah sastra lisan Sambas. Penerimaan dan sambutan itu menunjukkan bahwa struktur $R A$ fungsional bagi masyarakat Sambas, khususnya masyarakat Setale'. Dari struktur yang fungsional itu tentulah terdapat pesan berupa nilainilai budaya; dan, nilai-nilai budaya itulah yang hendak dicari, dikaji, dan dipahami.

Terdapat empat pembicaraan mengenai RA. Empat pembicaraan dilakukan oleh Effendy (1992, 1994, 1995, 1997), sedangkan dua pembicaraan lainnya dilakukan oleh Effendy dkk. (1996 dan 2001). Effendy (1992, 1994, 1995) menyatakan bahwa bedande' sebagai satu jenis seni pertunjukan. Proses pendendangannya bersifat tertutup. Komentarkomentar yang diberikan penikmat sepanjang pendendangan teks tidak mempengaruhi pedande' dan teksnya. Dikatakan juga (Effendy, 1995:5) bahwa teks itu merupakan pencerminan protes masyarakat Setale' terhadap dominasi kesultanan Sambas. Untuk memperkuat pendapat tersebut, kehadiran $R A$ dikaitkan dengan sejarah lokal Setale'.

Pembicaraan yang cukup komprehensif mengenai teks $R A$ terdapat dalam laporan penelitian yang berjudul Citra Hero: Telaah Unsur Tokoh Teks Raje Alam (Effendy dkk., 1996). Menurut Effendy dkk. (1996:25), citra hero ketujuh unsur tokohnya tidak dapat dilepaskan dari peran Mambang Kuning. Pertalian hubungan Mambang Kuning dengan ketujuh keturunannya terwujud dalam bentuk pusaka, baik cinte maupun benda-benda pusaka. Dengan adanya pertalian itu, anak cucu Mambang Kuning memperoleh kejayaannya.

Selanjutnya, pembicaraan yang panjang lebar mengenai teks ini dilakukan lagi oleh Chairil Effendy dengan judul "Teks Raja Ngalam: Suntingan Teks, Terjemahan, Disertai Telaah Resepsi" (1997) yang kemudian diterbitkan dengan judul Teks Raje Ngalam: Diserta Telaah Resepsi (2001). Penelitian ini menelaah bahasa, formula, struktur teks, serta hubungan teks $R A$ dengan teks-teks lainnya. Dibicarakan pula hal-hal yang berkaitan dengan pemerolehan teks (model pembelajaran), model dan teknik penyajian teks di depan publik, pola lagu pendendangan, kedudukan pedande', dan lain sebagainya.

Kesemua pembicaraan mengenai $R A$ di atas belum menyinggung nilai-nilai budaya yang terdapat di dalam teksnya. Informasi dan pengetahuan mengenai nilai-nilai budaya penting untuk diketahui sebagai bahan bagi pembaca masa kini mempelajari sejarah perkembangan kebudayaan masyarakat pemilik teks.

Sastra lisan merupakan satu fenomena sosial budaya yang hidup di tengah masyarakat yang belum terpelajar maupun yang sudah terpelajar (Finnegan, 1977:3; Goody, 1992:14; bdk. Liaw, 1975:1). Pentransmisiannya dilakukan dari mulut ke mulut, dari satu generasi ke generasi berikutnya. Penyebarannya seirama dengan mobilitas komunitas pendukungnya (Thompson, 1977:5). Oleh sebab itu, di tempat-tempat yang secara geografis berjauhan dan di lingkungan 
kebudayaan yang relatif berbeda, kerap dijumpai teks-teks sastra lisan yang menunjukkan kemiripan, misalnya dalam hal motif (Finnegan, 1992b:163-5).

Kandungan isi sastra lisan bermacammacam. Ada yang berisi peristiwa yang dipandang oleh masyarakatnya benar-benar pernah terjadi di masa lalu, ada pula yang semata-mata rekaan. Dalam hal yang pertama, sastra li $\neg$ san dipandang merepresentasikan kenyataan (Hough, 1966: 45; Junus, 1993:2; Vansina, 1973:148). Dalam hal yang kedua, sastra lisan berisi berbagai hal, baik yang berkaitan dengan kehidupan manusia maupun binatang. Dari kandung $\neg$ an isinya itu, ada teks sastra lisan yang dianggap sakral seperti RA, di samping tidak sedikit yang profan.

Sastra lisan merupakan karya seni yang bersifat "sesaat". Begitu sebuah teks selesai dipentaskan, fenomena kesastraan yang persis sama tidak mungkin terulang kembali meskipun dilakukan oleh penutur yang sama (Goody, 1989:111; Okpewho, 1979:2). Faktor penyebabnya adalah "penyalinan" tidak dilakukan terhadap "naskah induk yang kongkret", tetapi pada "naskah induk yang imajiner" (Sweeney, 1973:20). Oleh sebab itu, setiap kali dipentaskan selalu terjadi perubahanperubahan. Adapun yang relatif tetap adalah inti cerita atau ba $\neg$ gian-bagian yang dianggap penting (Lord, 1976: 99; Hutomo dalam Sutrisno, 1981:18). Perubahan terjadi sesuai dengan kemampuan daya cipta penutur dan harapan penik $\neg$ matnya. Tidak ada wujud sastra lisan yang baku dan mantap; sastra lisan selalu dinamis, lincah, dan hidup (Lord, 1976:22; Teeuw, 1984:299).

Setiap teks lisan tentu memiliki struktur. Dalam pandangan teori struktural, setiap teks mengandaikan adanya kebulatan dan keutuhan yang terbentuk oleh jalinan seperangkat unsur. Tidak satu pun unsur dapat berubah tanpa menyebabkan reperkusi pada unsur-unsur lainnya (Riffaterre dalam Erhmann, 1970:190). Setiap unsur relasional dan fungsional dalam rangka struktur. Transformasi yang terjadi dalam struktur - transformasi inheren dalam struktur-tidak membutuhkan bantuan dari luar struktur. Kebulatan struktur dapat terbentuk dengan sendirinya karena ada $\neg$ nya sifat self-regulation (menurut Piaget, 1995:10).

Dalam visi Formalis, teks sastra bersifat otonom. Visi ini bertentangan dengan teks sastra sebagai fakta semiotik. Sejatinya, teks diciptakan untuk dikomunikasikan. Cara penikmatannya berbeda-beda sehingga hasilnya pun berbeda-beda pula. Dalam proses pembacaan dipahami bahwa struktur teks sastra tidak otonom. Struktur itu muncul dan hidup di dalam kesadaran penikmat (Mukarovsky, 1978:83). Ia merupakan hasil dari proses strukturasi pikiran pembaca. Teks sastra hanyalah sensor simbol yang memungkinkan terjadinya strukturasi itu (Mukarovsky, 1978:83). Struktur teks sastra, dengan demikian, adalah struktur yang dinamik.

Karya sastra dalam visi struktur dinamik merupakan hasil dari proses komunikasi dan kebudayaan secara luas (Fokkema dan KunneIbsch, 1977:32). Perubahan-perubahan yang terjadi di luar karya sastra, ba $\neg$ ik secara tidak langsung di bawah dampak perubahan sosial maupun secara langsung di bawah pengaruh perubahan yang terjadi secara bersamaan di dalam ranah kebudayaan seperti ilmu, kebudayaan, ekonomi, politik, bahasa, dan sebagainya turut mempengaruhi kedinamikan struktur es $\neg$ tetik (Mukarovsky dalam Erlich, 1981:256). Karena teks sastra memanifestasikan dirinya sebagai tanda dalam strukturnya dan juga dalam hubungannya dengan masyara $\neg$ kat, pencipta, dan penikmatnya, maka struktur teks sas $\neg$ tra sebagai artifak tidak berubah. Ia akan berubah, yakni menjadi "objek estetik", ketika dibaca oleh penik $\neg$ matnya (Mukarovsky dalam Fokkema dan Kunne-Ibsch, 1977:143). Dengan kata lain, struktur teks sastra menjadi hidup dalam proses pembacaan.

Dalam proses pembacaan, makna teks tidak secara otomatis dapat dipahami. Bukan tidak mungkin konvensi teks yang dibaca berbeda dengan konvensi yang dimiliki penikmat. Perbedaan itu menyebabkan horizon harapan penikmat mengalami pergeseran. Fenomena itu menunjukkan bahwa konvensi sastra bersifat luwes dan penuh dinamika (Teeuw, 1984:103). Konvensi lama mungkin 
diberontaki dan diganti dengan konvensi baru (Culler, 1977:147). Tujuannya adalah agar teks yang bersangkutan mempunyai greget dan menimbulkan efek puitik. Oleh sebab itu, dalam rangka pemaknaan teks diperlukan adanya kompetensi kesastraan (Culler, 1977:130). Dalam hal RA, yang dimaksudkan adalah kompetensi sastra lisan Melayu (Sambas).

Dalam proses pembacaan sekaligus "terbaca" nilai-nilai budaya. Nilai-nilai budaya itu terbaca melalui tindakan tokoh, peristiwa yang mengiringi keberadaan tokoh, maupun deskripsi-dekskripsi tekstualnya. Nilai budaya itu sendiri merupakan tingkat pertama kebudayaan ideal atau adat. Nilai budaya adalah lapisan paling abstrak dan luas ruang lingkupnya. Pada tingkat ini terdapat ide-ide yang mengonsepsikan hal-hal yang paling bernilai dalam kehidupan masyarakat. Oleh sebab itu, nilai budaya menjadi berfungsi sebagai pedoman tertinggi bagi kelakuan manusia (Koentjaraningrat, 1979:8-25).

Clyde Kluckhohn (dalam Pelly, 1994) merumuskan nilai budaya dalam lima kategori, ialah nilai budaya yang berkaitan dengan (1) hakikat hidup, (2) hakikat kerja atau karya manusia, (3) hakikat kedudukan manusia dalam ruang dan waktu, (4) hakikat hubungan manusia dengan alam sekitar, dan (5) hakikat hubungan sesama manusia. Kelima nilai budaya dimaksud tentu dapat dijabarkan lebih lanjut secara kontekstual. Dalam teks sastra boleh jadi ada nilai budaya yang dieksploitasi lebih intensif dibandingkan dengan nilai lainnya.

\section{METODE PENELITIAN}

Teks-teks sastra lisan Sambas yang mengisahkan tokoh Raja Alam adalah $\mathrm{R} A, D D$, $S G A, W U$, dan $A S K A$. Dalam penelitian ini, RA ditetapkan sebagai dasar kajian de-ngan dasar pertimbangan sebagai berikut. Teksnya memiliki jangkauan struktur yang luas, mulai dari adegan anak Mambang Kuning, Raja Sentang Muda, turun ke bumi mengawini Putri Dayang Dandi, sampai kepada adegan pertemuan kembali Awang Kesukma dan anaknya, Putri Si Telur Bujur, dengan istrinya, Putri Pelaik. Di samping itu, teks yang diawali oleh eksordium berupa mantra itu mengeksploitasi unsur BMS, $\mathrm{BM}, \mathrm{BA}$, dan idiolek sehingga totalitas bahasa teksnya tampak khas.

Untuk memenuhi tujuan penelitian, data diperoleh dari teks suntingan dan teks terjemahan yang sudah dilakukan oleh Chairil Effendy (1997). Data berupa kutipan, baik berupa formula, konstruksi formulaik, maupun bentuk-bentuk lainnya. Bentuk-bentuk data itu diperoleh melalui metode pembacaan heuristik, yang kemudian ditafsirkan melalui pembacaan hermeneutik (Rimmon-Kenan, 1986).

Usaha mengungkap struktur RA dilakukan dengan cara mencermati keterkaitan unsurunsur struktur yang mendasari terciptanya teks (poetics) kemudian menafsirkannya untuk mendapatkan arti teks (hermeneutics de Man, 1983:ix) dan nilai-nilai budaya teks. Tegangantegangan yang muncul itu dijembatani dengan metode pembacaan (Rimmon-Kenan, 1986). Pembacaan berjalan dalam dua tahap, yakni heuristik dan hermenuetik.

Untuk mendapatkan hasil yang diharapkan, analisis dilakukan dengan teknik sebagai berikut. Pertama, dicermati fungsi bahasa sebagai medium teks, ialah unsur BMS, BM, BA, arkais, idiolek, dan bentuk-bentuk stilisasi. Di sini terkait pula pencermatan terhadap formula dan konstruksi formulaik. Kedua, teks dibagi ke dalam unit-unit naratif yang setiap unitnya diberi label (Rimmon-Kenan, 1986:121). Ketiga, berdasarkan pencermatan atas relasi dan fungsi antarunsur struktur.

\section{HASIL PENELITIAN DAN PEMBAHASAN Eksordium dan Doa Selamat}

Eksordium merupakan semacam mantera yang diucapkan dengan suara perlahan oleh penutur teks sebelum teksnya didendangkan. Eksordium lazim digunakan dalam tradisi pelisanan teks di tengah masyarakat Melayu. Fungsi eksordium adalah "menghubungkan" penutur teks dengan satu kekuatan supranatural. Dalam "hubungan" tersebut, sang penutur hendak "menyatakan" bahwa teksnya bersifat sakral atau suci. 
Dilihat dari komposisinya, eksordium teks ini merupakan perpaduan antara nilai-nilai Islam, Hindu, dan lokal. Nilai-nilai Islam diwakili oleh shalawat Nabi Muhammad dan surah Al-Ikhlas; nilai-nilai Hindu diwakili oleh adanya penyebutan "Mambang Kuning Peri Kayangan Buta Raksasa Jin Berantai"; dan, nilai-nilai lokal diwakili oleh penyebutan "itulah seruanku, datanglah kepadaku, tunjukkan kepadaku semua yang kuminta, perlihatkan kebesaran Allah." Bentuk sinkretis nilai-nilai budaya ini lazim di tengah kebudayaan masyarakat Melayu Kalimantan Barat. Hal itu menunjukkan bahwa kebudayaan bersifat dinamis. Selalu terjadi tarik-menarik antara berbagai nilai di tengah masyarakat.

Dalam pada itu, doa selamat berfungsi untuk mengakhiri seluruh pertunjukan. Dengan doa selamat diharapkan seluruh unsur yang terlibat dalam pertunjukan, pedande' maupun penikmat, berada dalam keadaan selamat, tidak diganggu oleh mahluk-mahluk halus yang berasal dari laut, gunung, dan tempat-tempat lainnya.

\section{Bahasa, Formula, dan Konstruksi Formulaik Teks}

Struktur bahasa teks $R A$ didasari oleh tata bahasa tradisional yang menyediakan seperangkat konstruksi kebahasaan. Sintaksis maupun semantis bahasa teksnya terpola dan bersifat formulaik (Scholes dan Kellog, 1981:50). Karakteristik itu merupakan hasil dari pengeksploitasian unsur-unsur bahasa Melayu Sambas (BMS), bahasa Melayu (BM), bahasa Arab (BA), arkais, dan idiolek sebagai keseluruhan ciri bahasa pedande' (Kridalaksana, 1983:62).

Unsur bahasa Arab yang dominan digunakan, bahkan menjadi ciri utama teks ini, adalah wa astagafirullah. Pemanfaatan istigfar ini agaknya berkaitan dengan estetika bedande'. Pedande' dalam pengertian implied author (menurut Martin, 1986:135) tidak mengetahui mengapa satu peristiwa terjadi atau mengapa satu tokoh melakukan tindakan tertentu di dalam teksnya itu.

Braginsky (1993:81-4) menyebutkan ada 3 aspek keindahan dalam sastra Melayu klasik, ialah (a) ontologis, (b) imanen, dan (c) psikologis. Dalam aspek pertama dibedakan antara "keindahan abadi" (jamal) dan "keindahan duniawi" (husn). Husn merupakan pembayangan dari jamal. Keindahan karya sastra sebagai produk kreasi manusia merupakan pencerminnn keindahan absolut yang merupakan kekayaan Allah. Aspek kedua berkaitan dengan 'perangkat-dalam' (inner properties) keindahan. Aspek ketiga berkaitan dengan efek keindahan bagi penikmat yang menyebabkannya terlena. Jadi, penggunaan istigfar sebagai formula teks merangkumi ketiga aspek estetika sastra Melayu klasik.

Idiolek merupakan keseluruhan ciri-ciri berbahasa seseorang (Kridalaksana, 1983:62), sedangkan stilisasi merupakan gejala bentuk-bentuk baku yang dimodifikasi (Sweeney, 1973:23). Keduanya relatif sulit dipisahkan secara tegas. Akan tetapi, sebagian bentuk stilisasi seperti nasalisasi terdapat pula dalam teks-teks sastra lisan Melayu (Malaysia, Sweeney, 1973, 1987) dan kaba di Sumatra Barat (Suryadi, 1993a, 1993b). Demikianlah di dalam teks $R A$ idiolek dan stilisasi dieksploitasi secara intensif dan ekstensif bagi signifikansi totalitas teksnya.

Formula dan konstruksi formulaik merupakan ciri khas sastra lisan (Lord, 1976; Finnegan, 1977). Pada teks $R A$, formula yang paling dominan adalah wa astagafirullah bagaikemane ngalang kupalang (terjemahan harfiahnya adalah 'wastagfirullah bagaimana alang-kepalang') yang bermakna 'permohonan maaf bahwa sang pedande' tidak mengada-ada, melainkan hanya menyampaikan apa yang dilihatnya" atau bagaikemane ngalang kupalang yang bermakna "ketidaktahuan". Dalam pada itu, konstruksi formulaik yang dimanfaatkan secara intensif dan ekstensif adalah bentuk-bentuk paralelisme seperti ngape gawai, ngape keraje ('apa gawai, apa kerja'); ngaku malu, ngaku supan ('aku malu, aku malu', supan berarti 'malu' dalam BI); ngilang kesah, timbol kesah ('hilang kisah, timbul kisah'); pandita dan ngalem ngulama ('pendita dan alim ulama'), atau singape punye ngakal, singape punye parentah ('siapa punya ide, siapa punya perintah'). Demikian pula deskripsi tentang perjalanan, peperangan, kecantikan perempuan, prosesi pernikahan merupakan bentuk-bentuk konstruksi formulaik yang siap pakai (stock-intrade).

\section{Struktur Umum Teks}

Struktur utuh satu teks selalu terdiri atas bagian awal, bagian tengah, dan bagian akhir 
(Aristoteles dalam Teeuw, 1984). Bagian awal berfungsi untuk membuka teks sekaligus mengantarkan bagian tengah teks. Bagian tengah memuat kisah (story) secara utuh. Selanjutnya, bagian akhir berfungsi menutup seluruh kisah yang tersaji di bagian tengah teks. Khusus untuk teks ini, patut dicatat adanya eksordium dan doa selamat. Keduanya memang bukan bagian dari teks, tetapi memiliki relasi dan fungsi dengan teks dan proses pendendangan teks. Tanpa eksordium, tidak ada pendendangan teks; tanpa doa selamat, tidak "penyelesaian" pendendangan teks.

\section{Bagian Awal Teks}

Bagian awal teks terdiri atas dua bagian, yakni mantera pembuka teks dan deskripsi percakapan antara Raja Sentang Muda dengan anaknya, Awang Darma dan Putri Dayang Dandi. Dalam bagian kedua teksnya dinyatakan bahwa Raja Sentang Muda merasa sudah tua dan, karenanya, dia berpesan agar kedua anaknya hidup akur satu sama lain.

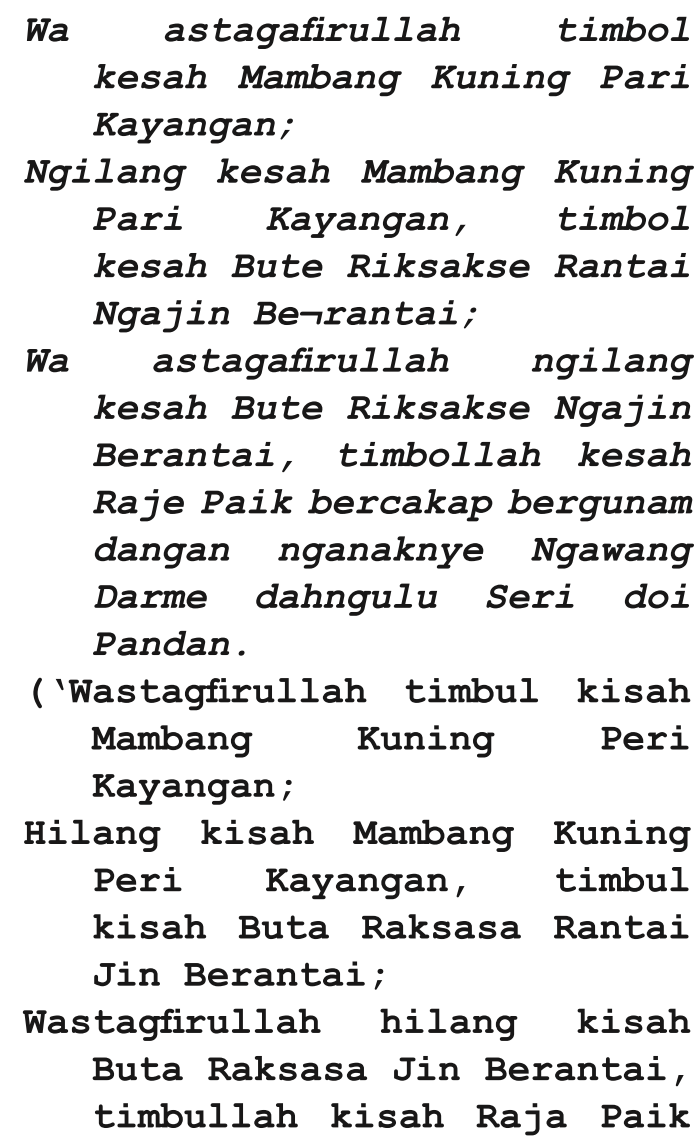

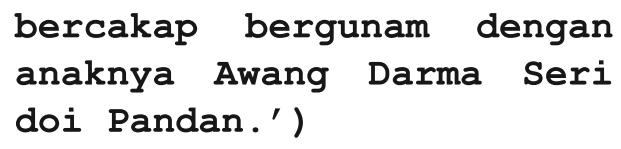

Mantera pembuka teks selalu difungsikan setiap kali pendendang memulai teksnya, setelah "istirahat panjang". Untuk diketahui bahwa teks utuh RA didendangkan selama 28 (dua puluh delapan) malam. Setiap malamnya, pendendangan teks lazimnya dimulai pukul 20.00 hingga pukul 24.00 WIB. Di antara masa itu terjadi dua atau tiga kali istirahat, biasanya antara 15 hingga 30 menit. Pendendangan teks setelah istirahat singkat tidak diawali dengan mantera; dengan kata lain, pelibatan mantera dilakukan pada waktu pendendang memulai pendendangan teksnya pada malam ke-1 hingga malam ke-28.

\section{Bagian Tengah Teks}

Bagian tengah teks memuat kisah tentang zuriat Raja Alam. Bagian tengah ini dimulai ketika Raja Sentang Muda mengangkat Awang Darma menjadi raja dan ketika Awang Darma menitahkan prajuritnya menempatkan Putri Dayang Dandi Sari Negeri di mahligai tinggi. Dikatakan demikian sebab, setelah Putri Dayang Dandi ditempatkan di mahligai tinggi atau dipingit, plot cerita bergerak setahap demi setahap sesuai dengan hukum kausalitas.

Bilamana dilihat dari plot ceritanya, bagian tengah teks ini terdiri atas 7 (tujuh) episode. Ketujuh episode dimaksud adalah episode Raja Sentang Muda, episode Raja Alam, episode Awang Mega Sakti, episode Awang Kamarudin, episode Raja Saih, episode Awang Kebarin, dan episode Awang Kesukma. Bagian tengah teks berakhir manakala Awang Kesukma, Putri Pelaik, dan anaknya selamat dari ancaman Nenek Raja Sawah.

\section{Bagian Akhir Teks}

Bagian akhir teks ditandai dengan berakhirnya perjuangan Awang Kesukma melawan Nenek Raja Sawah. Awang Kesukma mendapatkan kemenangan. Lalu kemenangan itu dirayakan dengan berpesta pora. Dan, di 
akhir perjamuan, diadakan pembacaan doa selamat (menurut ajaran Islam) oleh pendeta dan alim ulama.

\section{Nilai-nilai Budaya \\ 1. Hakikat Kehidupan}

Hakikat kehidupan merupakan nilai budaya terpenting bagi manusia. Dalam konteks teks $R A$, ada beberapa hal yang patut dicatat. Pertama, teks ini menekankan pentingnya kedudukan supremasi zuriat Raja Alam. Berbagai kejadian dan peristiwa yang terjadi di seputar tokoh utama dan tokoh-tokoh lainnya berpusat pada terbangunnya hal tersebut. Supremasi yang berarti kekuasaan tertinggi, tidak tertandingi, mula-mula terbaca dari gelar Raja Alam yang berbunyi "Raja Alam Penguasa Delapan Penjuru Dunia". Gelar atau julukan ini yang kemudian dijaga dengan sungguh-sungguh, baik oleh Raja Alam maupun oleh anak keturunannya. Berbagai peristiwa penting yang dapat dimaknai sebagai usaha menjaga nilai-nilai keunggulan dimaksud antara lain (1) Raja Alam menundukkan Raja Jin, (2) Raja Alam membawa kembali istrinya yang diculik oleh adik-adik Raja Jin, (3) Awang Mega Sakti membumihanguskan negeri kayangan dalam rangka membalas dendam penganiayaan terhadap ibunya, (4) Awang Mega Sakti dan burung burak emas membawa bangunan mahligai Putri Bungsu dari kayangan ke bumi, (5) Awang Mega Sakti mengalahkan Sari Panji, unsur tokoh yang menguasai samudra, (6) Awang Kamarudin berhasil mengubah wajahnya menjadi seperti Sari Panji atas bantuan Mambang Kuning di kayangan sehingga dengan itu dia dapat mengawini Putri Mayang Mengurai, (7) Awang Kebarin atau Raden Beruk menaklukkan Raja Muda yang kejam, (8) Awang Kebarin menolong dan menampung orang-orang lemah tidak berdaya, dan (9) Awang Kesukma berhasil mengalahkan Nenek Raja Ular Sawah.

Kedua, menegakkan kebenaran dan keadilan. Nilai ini paling menonjol terlihat ada pada diri Awang Mega Sakti dan Awang Kebarin. Oleh teksnya dikabarkan bahwa Awang Mega Sakti sudah merencanakan untuk membalas dendam, dalam rangka menegakkan kebenaran dan keadilan, manakala dirinya masih berada di dalam kandungan ibunya. Sang ibu, ialah Putri Selindung Bulan, diculik dan disiksa oleh adik-adik Raja Jin. Berbagaibagai siksaaan yang dialami Putri Selindung Bulan tidak membuat putri itu mati karena "tali nyawanya dipegang oleh anaknya", ialah yang kelak bernama Awang Mega Sakti. Rencana balas dendam itu dapat dia realisasikan manakala burung burak emas miliknya dapat menerbangkan dirinya ke kayangan.

Tokoh lain yang oleh teks dieksploitasi secara intensif dan ekstensif komitmennya terhadap kebenaran dan keadilan adalah Awang Kebarin atau Raden Beruk. Disebut sebagai Raden Beruk karena tokoh ini menyamar sebagai beruk. Ia menyamar sebagai beruk karena sejak bayi "dibuang" bapaknya di kaki Gunung Cupu Gading. Agaknya kenyang dengan berbagai penderitaan, tokoh ini kemudian tampil sebagai pembela kebenaran dan keadilan. Dia tidak saja menegakkan kebenaran dan keadilan kepada tokoh-tokoh lain, melainkan kepada orang tuanya sendiri, Raja Saih. Manakala diketahuinya bahwa bapaknya berusaha menurunkan dandang tembaga (kapal) peninggalan nenek moyangnya dari atas bukit dengan menggalangkan perempuan bunting jolong (hamil untuk pertama kalinya), maka Raden Beruk habis-habis memarahi bapaknya.

('Wastagfirullah Raden Beruk merah padam mukanya,

Sambil marah ke ramanya apa rupa garuk apa rupa kijat, apa rupa empak Beruk si Raden Beruk.

Wastagfirullah, "Rama oh Rama, begitukah rupanya akal Rama menjadi raja!

Sudah putih kepala hendak membunuh semua rakyat, berapa hilangnya?

Pernahkah orang mengulurkan dandang tembaga pakai galang dengan orang bunting doi naring.

Kalau seperti itu tidak berfaedah Rama menjadi raja.

Begitu lamanya dari muda tua sampai ke tua, begini rupanya akal Rama. 
angin", untuk "melihat cupak gantang orang di negeri orang", dan untuk "melihat adat bahasa orang." Dalam rangka itu, lautan dan samudra menjadi "jalan tol" yang dimanfaatkan dengan optimal. Raja Alam mengarungi lautan dari umur tiga tahun hingga dewasa, Awang Mega Sakti mengarungi angkasa dengan burung burak emasnya, Awang Kamarudin bertarung di lautan melawan Sari Panji, Raja Saih membongkar bukit untuk mengeluarkan harta karun peninggalan nenek moyang berupa dandang tembaga, Awang Kebarin mengarungi lautan dan padang pasir yang sangat luas untuk menyelamatkan orang-orang yang dikasihinya, dan Awang Kesukma masuk hutan ke luar hutan membawa anaknya dari kejaran Nenek Raja Ular Sawah. Pada bagian akhir teks, melalui doa yang diucapkan alim ulama, dapat pula dibaca bahwa teks $R A$ menekankan pentingnya harmoni antara manusia dengan alam sekitarnya agar manusia tidak mendapat bala.

("Lalu mengeluarkan makan-makanan, ketupat lepat dikeluarkan bala menolak bala.

Lalu disuruh alim pendita doa membaca doa, terus dibacakan doa oleh alim pendita ulama di dalam negeri.

Maka bersukacita sudah selesai pulangmemulangkan:

Asal gunung pulang ke gunung, asal pinang pulang ke tandan, asal kayangan pulang ke kayangan.

Dan asal laut pulang ke laut, asal tembakau pulang ke keranjangnya.

Dan habislah sudah, usai sudah membaca doa alim pendita:

Asal kayangan pulang ke kayangan, asal gunung kamu pulang ke gunung.

$$
\begin{gathered}
\text { Jangan datang jangan } \\
\text { mengacau lagi ngaru } \\
\text { jangan mengaru. }
\end{gathered}
$$

Sudah sedia santapan untuk membalas budi, ada sedia cukup tempat di dalam tempat.")

\section{Hakikat Hubungan Sesama Manusia}

Dalam hal ini, terdapat beberapa hal yang patut dikemukakan. Pertama, kesantunan dan ketaatan pada orang tua. Nilai ini cukup intensif dan ekstensif dieksploitasi. Sejumlah peristiwa yang dapat diajukan sebagai bukti untuk masalah ini, antara lain, (1) Raja Sentang Muda selalu meminta restu kepada Mambang Kuning Peri Kayangan setiap kali hendak turun ke dunia, menemui istri dan anaknya; (2) Raja Alam tidak berani pergi "bermain ombak bermain angin" ke negeri orang sebelum mendapat izin dari orang tuanya; (3) Awang Mega Sakti dengan burung burak emasnya membawa mahligai Tuan Putri Bungsu dari kayangan hingga ke bumi untuk dipersembahkan kepada ibu-bapaknya; (4) Awang Kebarin selalu meminta restu kepada ibunya setiap kali hendak melakukan perjalanan jauh menumpas kejahatan, (4) Awang Kebarin tidak bosan-bosan mengingatkan bapaknya agar bertindak bijaksana dalam memimpin kerajaan

Kedua, kasih sayang antarsesama terbaca juga melalui unsur tekstualnya dalam berbagai episode. Raja Sentang Muda mengingatkan agar istrinya, Dayang Dandi, dan abang iparnya, Awang Darma, selalu menjaga hubungan yang baik. Raja Alam selalu memperhatikan rakyatnya selama bertahuntahun mereka berkelana "bermain ombak, bermain angin, melihat cupak gantang orang di negeri orang." Awang Kebarin pun demikian selalu langsung bergerak manakala mendengar ketidakberesan dan ketidakadilan yang menimpa orang-orang.

\section{Hakikat Ruang dan Waktu}

Teks $R A$ memiliki konsep yang lentur atau relatif ihwal hubungan manusia dengan ruang dan waktu. Sebagaimana terbaca dari unsurunsur tekstualnya, yang terpenting adalah story ('cerita'); soal di mana dan bilamana actions ('tindakan') dan events ('kejadian') yang membentuk story (Rimmon-Kenan, 1986) itu terjadi tidaklah penting. Demikianlah teks $R A$ dengan mudah mengeksploitasi "dunia 
kayangan" dan "dunia bawah angin" (baroh angin). Dalam eksploitasi itu, tokoh-tokoh kayangan dan bawah angin sama-sama memiliki kelebihan dan keterbatasan. Mereka dapat saling mengunjungi, berinteraksi, dan membina hubungan dengan segala dinamikanya. Tidak terdapat "pantang-larang" yang membatasi unsur tokohnya bergerak ke mana pun mereka suka. Desa-kota, daratanlautan-angkasa adalah tempat "bermain" dan mengisi hidup.

Khusus tentang dimensi waktu, sebagaimana lazim dalam teks-teks lisan, penggunaan waktu dalam teks $R A$ juga bersifat magis. Kerapkali digunakan angka-angka 3, 7, 40, atau 100 untuk menunjuk rentang waktu tertentu. Perjalanan jauh yang seharusnya ditempuh tiga tahun dapat dilalui hanya dalam waktu 3 hari/bulan; perkelahian yang seru dikisahkan terjadi selama 40 hari 40 malam. Perhatikan contoh berikut.

\section{Hakikat Kerja}

Ihwal hakikat kerja, teks $R A$ memberikan gambaran yang variatif. Raja Alam dikisahkan sebagai orang muda yang piawai mengemudikan kapal berbulan-bulan lamanya dan memasak ikan hiu untuk semua penumpang kapalnya. Raja Saih dikisahkan sebagai raja yang "gila" kerja siang malam mengurus kerajaannya sampai-sampai tidak mengurus dan memperdulikan anaknya. Awang Kesukma dikisahkan sebagai seorang anak manusia yang sejak kecil hingga dewasa selalu membuat patung sampai satu hari dia jatuh cinta dengan patung ciptaannya sendiri. Awang Kesukma akhirnya dikawinkan dengan patung ciptaannya itu setelah dihidupkan oleh seorang pertapa berambut putih yang bertapa di Gunung Hijau.

Teks $R A$ secara khusus menyinggung mentalitas orang Melayu dalam bekerja. Dalam episode Awang Mega Sakti dikisahkan bahwa Awang Mega Sakti meminta dibuatkan burung burak emas. Raja Alam menyediakan satu bongkah emas dan menyuruh 7 orang tukang, salah satunya adalah Tukang Melayu, untuk membuat burung burak emas. Teks mengindikasikan bahwa 6 orang tukang bekerja serius, sedangkan Tukang Melayu hanya diam memperhatikan. Akan tetapi, ketika burung burak emas sudah jadi, tetapi tidak bisa terbang, Tukang Melayu-lah yang "menghidupkan" burung itu sehingga dapat membawa Awang Mega Sakti terbang ke kayangan. Dikisahkan oleh teksnya bahwa burung burak itu memiliki nyawa setelah Tukang Melayu melakukan shalat hajat 2 rakaat sebanyak 7 kali. Peristiwa tektual ini mengirim pesan bahwa orang Melayu lebih memiliki kemampuan spiritual daripada kemampuan

\section{KESIMPULAN}

Teks $R A$ merupakan teks lisan yang datang dari masa lalu. Dalam proses transmisinya ia berada dalam dinamika penerimaan atau penyambutan dengan teksteks lain sehingga terbentuklah sebagaimana wujudnya saat ini. Sebagai teks yang telah melintasi entah berapa zaman, teks $R A$ yang disampaikan dengan cara didendangkan dengan media bahasa lisan yang berasal dari unsur Bahasa Melayu, Bahasa Arab, idiolek, dan bentuk-bentuk stilisasinya, memiliki struktur yang khas. Strukturnya diapit oleh eksordium dan doa selamat.

Teks $R A$ jelaslah tidak muncul dari kekosongan budaya. Ia muncul di tengah masyarakat dan, dengan demikian, ia berisi nilai-nilai budaya masyarakatnya. Dengan kerangka teori nilai budaya Clyde Kluckhohn, kekayaan nilai budaya yang dikandungnya berbeda-beda. Bukan tidak mungkin penelitian lebih lanjut akan mendapatkan pemahaman lebih jauh mengenai kandungan nilai budaya di daslam teks ini.

\section{DAFTAR PUSTAKA}

Baried, Siti Baroroh dkk., 1985. Pengantar Ilmu Filologi. Pusat Pembinaan dan Pengembangan Bahasa. Departemen Pendidikan dan Kebuayaan. Jakarta.

Culler, Jonathan. 1977. Structuralist Poetics. Stucturalism, Linguistic and the Study of Literature. Routledge dan Keegan Paul. London dan Henley.

Effendy, Chairil. 1992. "Sastra Lisan Sambas: Suntingan Teks, Terjemahan, Struktur dan Fungsi.” Tesis S-2 UGM. Yogyakarta. 


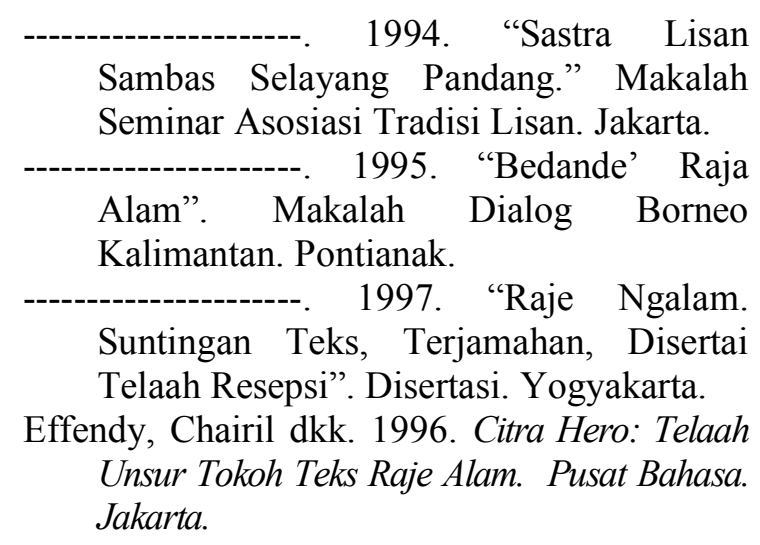

--. 2001. Teks Raje Ngalam. Telaah Struktur dan Fungsi. Departemen Pendidikan Nasional. Jakarta

Erlich, Victor. 1981. Russian Formalism. History-Doctrine. Yale University Press. New Haven dan London.

Finnegan, Ruth. 1992b. Oral Tradition and the Verbal Arts: A Guide to Research Practices. Routledge. London dan New York.

Fokkema, D.W. dan Elrud Kunne-Ibsch. 1977. Theories of Literature in the Twentieth Century. C. Hurst. London.

Goldmann, Lucien. 1981. Method in the Sociology of Literature. Basil Blackwell. Oxford.

Goody, Jack. 1992. "Oral Culture”. Dalam Richard Bauman (Ed.), Folklore, Cultural Performances, and Popular Entertainments: $A$ CommunicationCentered Handbook. Oxford University Press. New York.

Hassan, Fuad 1985. "Sastra sebagai Layar Proyeksi”. Makalah Penataran Sastra. Bogor.

Hough, Graham. 1966. An Essay on Criticism. W.W. Norton. New York.

Hutomo, Suripan Sadi. 1993. Cerita Kentrung Sarahwulan di Tuban. Pusat Pembinaan dan Pengembangan Bahasa. Departemen Pendidikan dan Kebudayaan. Jakarta.

Junus, Umar. 1993. Dongeng tentang Cerita. Dewan Bahasa dan Pustaka. Kuala Lumpur

Kartodirdjo, Sartono. 1992. Pendekatan Ilmuilmu Sosial dalam Metodologi Sejarah. Gramedia. Jakarta.
Kendon, Adam. 1992. “Gesture”. Dalam Richard Bauman (Ed.), Folklore, Cultural Performances, and Popular Entertainments: A CommunicationCentered Handbook. Oxford University Press. New York.

Koentjaraningrat, 1979. Pengantar Ilmu Antroplologi. Aksara Baru. Jakarta.

Laurenson, Diane T. dan Alan Swingwood. 1972. The Sociology of Literature. Mac Gibbon \& Kee. London.

Liaw, Yock Fang. 1975. Sejarah Kesusastraan Melayu Klasik. Pustaka Nasional. Singapura.

Lord, Albert B. 1976. The Singer of Tale. Atheneum. New York.

Mukarovsky, Jan. 1978. Structure, Sign and Function. Selected Essay by Jan Mukarovsky. Diterjemahkan dan disunting oleh John Burbank dan Peter Steiner. Yale University Press. New Haven.

Okpewho, Isidore. 1979. The Epic in Africa. Toward a Poetics of the Oral Performance. Columbia University Press. New York.

Osman, Mohd. Thaib. 1988. Bunga Rampai. Aspects of Malay Culture. Dewan Bahasa dan Pustaka. Kuala Lumpur.

Pelly, Usman. 1994. Teori-teori Sosial Budaya. Proyek Pembinaan dan Peningkatan Mutu Tenaga Kependidikan. Ditjen Dikti dan Kebudayaan. Jakarta.

Piaget, Jean. 1995. Strukturalisme. Diterjemahkan oleh Hermoyo. Yayasan Obor Indonesia. Jakarta.

Riffaterre, Michael. 1970. "Describing Poetics Structure: Two Approach to Baudelaire's les Chats." Dalam Jacques Erhmann (ed.), Structuralism. Doubleday. New York.

Rimmon-Kenan, Shlomith. 1986. Narrative Fiction: Contemporary Poetics. Methuen. London dan New York.

Sutrisno, Sulatin. 1981. Relevansi Studi Filologi”. Naskah Pidato Pengukuhan Guru Besar pada FS UGM. Yogyakarta.

Sweeney, Amin. 1973. "Professional Malay Story-Telling: Some Questions of Style and Presentation." Dalam JMBRAS. Volume XLVI, Part 2, Desember, h. 1-53. 
Teeuw, A. 1984. Sastra dan Ilmu Sastra. Pengantar Teori Sastra. Pustaka Jaya. Jakarta.

Thompson, Stith. 1977. The Folktale. University of California Press. Oxford

Vansina, Jan. 1973. Oral Tradition. A Study in Historical Methodology. Penguin Books. Harmondsworth. 